\title{
EXPERIÊNCIAS DO MOVIMENTO E A FORMAÇÃO DO PROFESSOR DE DANÇA
}

\author{
K. O. PORPINO \\ Universidade Federal do Rio Grande do Norte \\ kporpino@gmail.com
}

Artigo submetido em novembro/2014 e aceito em novembro/2014

DOI: $10.15628 /$ holos.2014.2555

\section{RESUMO}

O presente projeto tem como objeto de investigação as experiências do movimento como referências para a formação do professor de dança. Compreende-se a experiência a partir da fenomenologia de Merleau-Ponty, como modo de ser no mundo e delimitam-se para a investigação as experiências relacionadas à cultura de movimento, em geral, e a dança, em particular. Interessa questionar como o movimento mobiliza o sujeito e interfere em sua formação como professor de dança. Do ponto de vista metodológico a pesquisa orienta-se pela Fenomenologia, com enfoque na produção de narrativas escritas do próprio pesquisador e outros professores artistas da cidade de Natal-RN-Brasil. Nesse sentido, espera-se que a investigação seja capaz de apontar perspectivas para a formação do professor de dança que parta primeiramente de sua própria experiência como ser dançante, dinâmica essa necessária à vinculação do professor a área de conhecimento que exerce a docência.

PALAVRAS-CHAVE: Experiência, movimento, formação docente, dança

\section{MOVEMENT EXPERIENCES AND DANCE TEACHER TRAINING}

\begin{abstract}
This Project has as object of study movement experiences as references to the training of dance teacher. It comprises that the experience from the phenomenology of Merleau-Ponty as a way of being in the world and delimiting to research the experiences related to the movement's culture in general, and, particularly, dance. It interests asking how the movement mobilizes the individual and interferes in its training as a dance teacher. From a methodological point of view, research is guided
\end{abstract}

by phenomenology, focusing on the production of written narratives of its own researcher and other teachers-artists of the city of Natal, RN - Brazil. In this sense, it's expected that the research is able to point out perspectives for dance teacher training and that first starts from its own experience as a being who dances, dynamic that is needed to link the teacher to the field of knowledge that it exerts teaching.

KEYWORDS: Experience, movement, teacher training, dance. 


\section{INTRODUÇÃO}

O texto a seguir apresenta pesquisa que tem como objeto de investigação as experiências do movimento no contexto da formação do professor de dança. O termo experiências do movimento refere-se às experiências que englobam o movimento da dança especificamente, como também outras práticas corporais ${ }^{1}$ que dela se aproximam. A junção das duas palavras, experiência e movimento, contrapõe-se à visão que, historicamente, vinculou o movimento, prioritariamente ou exclusivamente, ao seu aspecto mecânico. Compreendido a partir dos estudos de MerleauPonty $(1994,2002)$ o termo experiência do movimento, considera o movimento como modo de habitar o mundo pelo sujeito a partir da intencionalidade e do perfil estesiológico que configura a experiência de mover-se. Nessa direção, a experiência é considerada como "iniciação aos mistérios do mundo", tal qual afirmou Merleau-Ponty. Essa compreensão distingue-se da visão empirista que entende a experiência como resposta a estímulos sensoriais externos que se encadeiam para gerar a percepção ou da visão intelectualista que a pensa como "inspeção intelectual". A experiência de movimento é compreendida nessa pesquisa como nosso modo de ser no mundo, como forma de percepção da própria existência. Chauí (2002) comenta que, em várias obras, Merleau-Ponty destaca a experiência do artista para vislumbrar no ato de pintar ou escrever um mundo visível e falante e discutir a experiência como uma cisão que não separa, em que o artista e sua obra se aproximam e se distanciam; estão entremeados mas não se confundem. Nessa perspectiva, compreendemos que o indivíduo desenvolve modos próprios de atuar profissionalmente frente à diversidade de experiências que compartilha no mundo com outras pessoas e em contextos diversos. Referimo-nos a uma formação contínua, que acompanha e move o indivíduo durante toda a sua preparação para a atuação profissional, inclusive extrapolando os ambientes de educação institucionalizada e o tempo cronológico.

A pesquisa origina-se de inquietações advindas de meu mundo vivido, especificamente de minhas próprias experiências de movimento que me fazem continuamente questionar e redimensionar minha atuação como professora e artista da dança. Essas inquietações estão situadas atualmente no contexto das relações estabelecidas com alunos, artistas e outros professores do Curso de Dança da Universidade Federal do Rio Grande do Norte (UFRN). A existência recente deste curso, na referida instituição, tem mobilizado o surgimento de questões diversas sobre o fazer e o ensinar dança, assim como também tem sido em outros contextos semelhantes em outras cidades brasileiras. A formação do professor de dança, no Brasil, nos últimos anos, ganhou significativo realce no contexto brasileiro com a criação de novos cursos de licenciatura no país, em virtude da criação de políticas do Governo Federal para incentivo à reestruturação das instituições de ensino superior. Desde a implantação do Curso de Dança da UFRN, em 2009, até os dias atuais, temos participado de discussões, em nível nacional, acerca dos modos pelos quais os novos cursos de dança se estruturam e organizam o conhecimento das várias áreas acadêmicas para formar o professor, como também o perfil dos professores desses cursos para a formação de novos professores de dança. Vários eventos da área de Dança e de Artes

\footnotetext{
${ }^{1}$ Na pesquisa nos referimos a práticas como o Tai Chi Chuan, a meditação, Lian Gong, Eutonia, dentre outras.
} 
Cênicas têm fomentado discussões acerca desses pontos ${ }^{2}$, assim como alguns autores têm investido em escrever sobre esse tema, como: Strazzacappa (2006, 2012), Wosniak (2009), Terra (2009), Rocha (2012), dentre outros. Nessas produções são destacadas as preocupações com os diversos campos de formação do professor de dança, sendo a universidade apenas um desses campos. Outro ponto destacado é a necessidade de considerar as interlocuções entre o fazer arte e o fazer docente na formação do professor artista. Para esta pesquisa, é importante considerar que a atuação do professor de dança está embebida por suas experiências do dançar em espaços diversos de sua formação anterior ou concomitante a sua formação acadêmica e a sua atuação profissional.

Com base nessa consideração, passei a refletir sobre como as experiências dos professores (e professores em formação universitária) com a dança (e com práticas afins) são tratadas no contexto de formação na universidade. Algumas questões para reflexão foram produzidas: 0 que a investigação dessas experiências pode revelar para a atuação do professor de dança? Como as experiências do movimento geram novas perspectivas de dançar, de pensar a dança e seu ensino? Como as experiências de movimento de professores e alunos podem ser consideradas na formação do professor na licenciatura em dança?

Pode parecer óbvio questionar sobre as experiências do dançar para os professores de dança, é fato que os professores só podem ensinar a partir de suas próprias experiências. No entanto nos referimos a como o professor é capaz de compreender suas experiências do dançar como desencadeadoras do fazer docente e, isso não está sempre dado de antemão. Vale lembrar a advertência feita por Merleau-Ponty (2004) de que o mundo que nos é revelado por nossa experiência de vida parece ser o que melhor compreendemos, no entanto isso é uma aparência, pois é esse mundo sensível que sempre estamos tentados a esquecer, em virtude de sua desvalorização por um pensamento prático e utilitário.

Com foco nessa reflexão, a pesquisa tem como objetivo descrever e interpretar experiências do movimento como possibilidade de identificar horizontes de significação para o dançar e o ensinar dança no contexto da formação do professor, como também organizar pontos de reflexão para o ensino da dança, tendo como foco uma atitude fenomenológica que considere a experiência do dançar como atualizadora das experiências de ensinar dança.

\section{2. UMA ATITUDE DE PESQUISA}

As questões mencionadas germinaram as primeiras iniciativas para a realização desta pesquisa e a movem a partir de uma atitude fenomenológica, tendo como referência principal o pensamento de Merleau-Ponty (1994), que assim define a Fenomenologia: “...tentativa de uma descrição direta de nossa experiência tal como ela é, e sem nenhuma deferência a sua gênese psicológica e as explicações causais que o cientista, o historiador ou o sociólogo dela possam fornecer..." (Merleau-Ponty, 1994, p. 2). Em nossa pesquisa, a referência da Fenomenologia se apresenta como tentativa de retornar ao mundo da percepção do movimento dançado, colocando entre parênteses o conhecimento produzido sobre dança para a ele retornar, tendo como

\footnotetext{
${ }^{2}$ Fórum Nacional de Coordenadores de Cursos Superiores em Dança, Reuniões Científicas e Congressos da Associação Brasileira de Pesquisa e Pós-graduação em Artes Cênicas, Seminário Dança Teatro Educação (UFCE), Encontro Científico da Associação Nacional de Pesquisadores em Dança.
} 
referência uma base existencial que possa fazer germinar novas compreensões sobre o mesmo e fundar novos horizontes de significação. É justamente recusando momentaneamente nossa cumplicidade e familiaridade com as evidências do mundo, que poderemos percebê-lo a partir de nossa existência imbricada com ele. Esse é o movimento da redução fenomenológica, que não busca uma essência absoluta, mas uma essência existencial, e por isso é preciso reconhecer que "O maior ensinamento da redução é a impossibilidade de uma redução completa" (Merleau-Ponty, 1994, p.10), e que não há pensamento "que abarque todo o nosso pensamento" (Merleau-Ponty, 1994, p.11) sobre o mundo.

Com foco no pensamento de Merleau-Ponty (2002), refletimos que o fazer arte e o ensinar não são somente ações advindas da acumulação e aplicação de procedimentos aprendidos de antemão, cujos significados se antepõem à experiência de quem atua, mas também formas de habitar o mundo e significá-lo em cada ato que pode ser percebido como uma criação que sempre se renova. É fato que a formação do professor de dança requer o acesso e a articulação de uma gama de conhecimentos de várias áreas acadêmicas; esse tema tem sido discutido por pesquisadores brasileiros ${ }^{3}$. Mas compreendemos que tal formação também requer a observação de como professores e alunos percebem sua própria maneira de produzir conhecimentos no contato com essas referências, de suas formas de sensibilizar-se com o mundo para produzir sua própria arte e seus modos de ensinar. "Tudo aquilo que sei do mundo, mesmo por ciência, eu o sei a partir de uma visão minha ou de uma experiência do mundo sem a qual os símbolos da ciência não poderiam dizer nada" (Merleau-Ponty, 1994, p.3)

Nossa intenção, portanto, é revelar as experiências de movimento como mobilizadoras não só do fazer artístico, mas também das práticas pedagógicas do professor, como possibilidade de um revisitar constante das próprias referências estéticas. Ainda, contribuir para a formação do docente autônomo, criativo e sensível que não se coloque refém das ideias alheias ou de padrões estéticos descontextualizados. Nesse ponto concordamos com o pensamento de Launay (2010, p.82) ao refletir que:

Quando as trocas começam a se endurecer e a se 'burocratizar', quando a gente quer a priori dominar o que se crê transmitir em nome da ideia do saber em dança, de uma ideia de si e do outro, quando a relação pedagógica diz respeito mais a observar as normas do que as inventar, talvez seja bom testemunhar, da maneira mais simples possível, as trocas e os gestos que nos fabricam.

Diante dos muitos conhecimentos sobre a dança a que temos acesso e produzimos no âmbito das instituições educativas, pretendemos refletir acerca de como os gestos nos fabricam, mas diante da compreensão de que também os fabricamos a partir de uma recíproca que significa a existência do indivíduo em seu contexto social e, especialmente, em seu contexto de formação como professor. Para esta pesquisa consideramos as experiências com a dança e com outras práticas corporais que dela se aproximam nos referindo às experiências pelas quais somos mobilizados, arrebatados, por um movimentar-se que rompe com o instituído e permite novos horizontes de sentidos sobre o dançar. Ao longo dos últimos anos, registramos experiências de movimento vividas em laboratórios de criação em dança (Ateliê Dança e Práticas Orientais) e em disciplinas ministradas para o Curso de Dança da UFRN (Pedagogia do corpo e Tópicos Especiais em Dança), situações em que pudemos registrar experiências do dançar e do ensinar dança. Para

${ }^{3}$ Marques (2003), Strazzacappa (2006). 
o registro dessas experiências fizemos uso de anotações em um diário para a construção de narrativas escritas, compreendendo-as como uma possibilidade de mergulho e submersão na experiência sensível. A utilização de diários como suporte de registro das experiências do dançar e a produção de narrativa como recursos técnicos para pesquisa fenomenológica já foram enfocadas em outros trabalhos, como o de Machado (2002) e Dutra (2002), respectivamente.

No que tange à produção de narrativas, tomamos como foco o pensamento de Benjamim (2012), para quem o narrador imprime na narrativa a sua marca, tal qual o oleiro em sua relação com a argila. "O narrador é a figura na qual o justo se encontra consigo mesmo", reflete o autor (Benjamim, 2012, p.240). Assim, a narrativa não se esgota, expressa Benjamim (2012) "Ela conserva suas forças e depois de muito tempo ainda é capaz de desdobramentos" (p.220). Portanto narrar, nesta pesquisa, não é somente contar um fato ou informar, mas também expressar as circunstâncias nas quais uma situação foi vivida e compartilhada para ali colocar a vida do narrador que também reconhece parte da experiência alheia como sua. A partir desse pensamento, produzimos as narrativas levando em consideração nossa própria experiência de movimento com apoio das anotações no diário, como também fizemos usos de depoimentos escritos e orais de alunos, artistas e outros professores envolvidos nas situações vividas a serem narradas.

As anotações advindas das experiências vividas nos ateliês nos levou à organização das vivências nas disciplinas, a partir das quais pudemos trabalhar a alguns temas recorrentes, como: o silêncio, a lentidão, o olhar, o toque e a presença; como também de algumas práticas corporais como o Tai Chi Chuan, a improvisação a partir de Rudolf Laban e Patrícia Stokoe (com o outro e com objetos), o Liang Gong e alguns elementos da técnica de Klauss Viana. A partir das experiências nas disciplinas, outras experiências passadas tornaram-se importantes, foram relembradas e passaram também a compor temas das narrativas.

Assim, ressaltamos a experiência do narrador que se entremeia e cria sentido no partilhar de outras vidas em temporalidades e espacialidades diversas. Tomando a Fenomenologia como atitude, não buscamos explicar a experiência que dá forma à narrativa, tampouco nos separarmos dela para entendê-la, mas compreendê-la por ela mesma, como forma de habitar o mundo, em sua relação sensível com ele. Aqui nos aproximamos com a ideia de uma "biografia sem fatos", a exemplo do que retrata Fernando Pessoa em seu Livro do Desassossego, "Faço paisagens com o que sinto" escreve via Bernardo de Campos; as frases se revelam pela sensibilidade que geram e não por uma descrição cronológica de fatos (Pessoa, s.n., p.45).

\section{DANÇAR E NARRAR COMO POÉTICAS DO PRESENTE: ALGUMAS REFLEXÕES}

As ações de dançar e narrar no contexto dos espaços de investigação da pesquisa, já mencionados, têm nos levado a uma reflexão mais atenta sobre o tempo, e mais especificamente sobre o presente. Passamos a pensar nesse tema na medida em que não experimentamos nossa dança nos ateliês, nem registramos as experiências de movimento nas narrativas com foco na ideia de um tempo linear, mas como experiências para enxergar que, se encontramos algum sentido em experiências passadas, é porque elas se fizeram presentes em nós e foram capazes de realçar horizontes de significação no momento presente. Este é, inclusive, um ensinamento da Fenomenologia, "voltar às coisas mesmas" ou à experiência sensível, tal qual ela se mostra aos nossos sentidos, deixando de lado os modelos explicativos sobre ela. Refletimos que é o tempo 
vivido como dimensão da existência que permite organizar minha experiência de narrar e de dançar; minha subjetividade não está no tempo, mas confunde-se com ele. Para Merleau-Ponty (1994, p.568)

Só existe tempo para mim porque estou situado nele, quer dizer, porque me descubro já envolvido nele,... Existe tempo em mim porque tenho o presente. É vindo ao presente que um momento do tempo adquire a individualidade indelével, o 'de uma vez por todas' que lhe permitirão em seguida atravessar o tempo e nos darão a ilusão da eternidade. Nenhuma das dimensões do tempo pode ser deduzida das outras. Mas o presente (no sentido amplo, com seus horizontes de passado e porvir originários) tem, todavia um privilégio porque é a zona em que o ser e a consciência coincidem.

Para o autor a temporalidade não é exterior ao sujeito, o tempo não é uma sucessão de acontecimentos cabíveis de registro, mas nasce da relação do sujeito com as coisas, o que é passado e futuro para ele habita o presente. Nessa perspectiva o tempo não é enfocado aqui como um objeto do nosso saber que necessitamos acessar para a compreensão de nossa dança e construção de uma narrativa, mas é inerente à experiência de dançar e narrar, uma vez que pode ser pensado como "uma dimensão do nosso ser" (Merleau-Ponty, 1994, p.557). No ato de narrar, vive-se, assim, uma confluência do tempo passado e futuro no momento presente da narrativa. Uma vez registrado esse tempo vivido pelo narrador, ele pode distender-se em inúmeras interpretações. Assim também é na dança, vive-se no presente a confluência dos gestos já vividos e projetam-se novas perspectivas de execução.

Com base no pensamento de Merleau-Ponty, Chauí (2002) reflete que: "A experiência é o ponto máximo de proximidade e de distância, de inerência e diferenciação, de unidade e pluralidade em que o mesmo se faz outro no interior de si mesmo" (p.164). Se a experiência da visão pode ser descrita como "o que em nós se vê quando vemos", poderíamos afirmar que a experiência de narrar pode ser compreendida como o que em nós se torna narrativa quando narramos. Assim é também a dança, o que se move em mim quando me movo. A dança não existe em si como coisa ou ideia, mas entrelaça o dançante e o dançável no momento em que ocorre a dança, na própria existência de quem dança.

Essa ideia alimenta-se também do pensamento de Sheet-Jonstone para quem descrever a dança por ela mesma, a partir de uma atitude fenomenológica, constitui-se um verdadeiro desafio, pois voltar-se à experiência do dançar é perceber uma dimensão nem sempre evidente ao olhar do público (in Alarcon, 2011). A autora lembra a frase do poeta Yeats, que questiona: '...como podemos distinguir o dançarino da dança?' como uma provocação que a faz pensar quão incomum é a relação entre o dançarino e a dança, uma vez que ao dançar o dançarino não se move através de uma forma, mas uma forma se move através dele, assim não é possível separá-lo de sua dança. Segundo Sheets-Johnstone, em entrevista a Mônica Alarcón, o movimento na dança é criado na medida em que a dança é executada, e sua "integridade estética" predomina sobre qualquer mensagem ou narrativa que a justifique em seu contexto social, portanto a dança não se reduz ao simbólico. Ao investigar movimentos advindos da Dança-improvisação, a autora reflete que a dança é mais do que se quer dizer com ela, seu movimento é mais que um discurso sobre algum assunto ou a justaposição de um sentido ou emoção, o movimento fala por si mesmo (in Alarcón, 2011). 
A ideia de uma "biografia sem fatos" como narrativas de experiências do movimento do dançar nos faz retomar as palavras de Merleau-Ponty (1994) ao esclarecer que, embora a Fenomenologia permita ao pesquisador aproximar-se da experiência tal qual ela é vivida, longe das explicações que possam a ela estar atreladas, ela não substitui a experiência tal qual ela ocorre, é sempre descrição após o fato. As palavras de Stern (2007), ao tratar da narrativa no processo psicoterápico com base na fenomenologia, ajudam-nos a entender a narrativa em nossa pesquisa "Numa narrativa, o agora do qual se fala já aconteceu. Ela cria uma relação entre os agoras passado e futuro. Não é uma experiência direta. Apenas a narração está acontecendo agora" (p.28).

A busca por tomar consciência desse momento presente, comumente eclipsada pelo nosso apego ao passado e ao futuro, tem levado vários processos psicoterápicos a voltar-se para a vivência do presente, antes e após a perspectiva fenomenológica de Merleau-Ponty (Stern, 2007). O autor esclarece sobre o momento presente como sendo "...a experiência sentida do que acontece durante um breve período de consciência" (p.54), é a experiência vivida originalmente, a partir da qual se produz uma narrativa posterior. A ideia de que esse momento presente trata-se de uma experiência subjetiva construída de modo ativo por nosso corpo e nossa mente trabalhando juntos tem referências em vários estudiosos, como Sheets-Johnston; Damásio; Varela, Thompson e Rosch, dentre outros (Stern, 2007).

Nas leituras sobre as práticas orientais, como o Tai Chi e a própria meditação, observamos que esse estado de estar presente também está relacionado à articulação dos processos mentais e corporais (Huang, 1979; Da Liu, 2004). A partir da visão psicoterapêutica da Biossistêmica, Stupiggia também faz referência a essa articulação como preponderante para que compreendamos a emoção e assim possamos restabelecer uma relação do indivíduo consigo mesmo e com o fluxo energético de sua vida. $O$ autor, inclusive, cita o Zen como uma referência que podemos ter como exemplo de uma imersão completa no estado de presença, de tornar-se presente. $\mathrm{O}$ estar presente para o autor está vinculado à capacidade de se emocionar ou de reatar os processos corporais aos processos mentais na experiência do indivíduo.

Essa discussão torna-se importante no campo da dança, uma vez que a dança, como toda arte, parte das relações que o homem estabelece com o mundo, de suas sensibilidades diante da vida e, por que não dizer, das emoções que recrutam o sentido dado pelo pensamento às ações corporais. Nesse sentido, o ato de dançar pode ser compreendido como um ato de conhecimento de si mesmo, assim como propõe um trabalho psicoterápico na Biosistêmica, o pensamento Zen, ou uma prática oriental como o Tai Chi Chuan. A imersão no presente, na emoção que emana de suas próprias experiências reflete-se na ampliação das capacidades expressivas do dançarino, seja para criar seu próprio movimento, seja para dar sentido ao movimento supostamente criado por outro, pois só posso me expressar a partir do movimento dado quando sou eu mesmo, quando posso reconhecer minha própria emoção ao executar um movimento. Poderíamos dizer que o movimento se transforma em dança quando é possível viver no presente a emoção que o alimenta, que o diferencia de outro movimento qualquer utilitário ou estetizado a partir de referências estéticas que estão além do entendimento de quem dança.

Essas reflexões levam-nos a reconhecer que o aprendizado da dança, longe de se resumir ao ensino de passos codificados, embrenha-se em um campo muito mais amplo de aprendizado que perfaz todo o caminho de conhecer-se como pessoa e estar aberto para viver uma experiência intensa, seja harmônica, seja desconcertante. Estar aberto para a dança, nesse sentido, é estar aberto para conhecer-se, mesmo que em segredo, é estar disponível para tomar consciência do 
fluxo energético que faz pulsar a existência, querer conhecer suas intensidades, seus limites e possíveis entraves ainda a descobrir.

As experiências nos ateliês individuais e com outros artistas têm nos mostrado que a dança também pode situar-se em um campo aprofundado de percepção que compreende o estado meditativo como maneira mais alargada de compreensão do dançar e do próprio artista. Nesse contexto, consideramos que algumas experiências de movimento advindas de práticas orientais, como o Tai Chi Chuan e a Yoga, nos permitem vivenciar um estado de atenção prolongada do presente. Essa experiência, diferente do que Daniel Stern denomina momento presente, parece aproximar-se dos estudos sobre a atenção plena (metaconsciência) presente na área da medicina a partir dos anos 1970.

O Tai Chi Chuan, assim como outras práticas meditativas vividas nos ateliês, presentes na filosofia não-ocidental, leva à percepção dos fluxos energéticos que nos mantém vivos e conectados ao universo, uma observação atenta, a partir da qual é possível a contemplação da própria experiência pelo praticante no momento em que ela ocorre. Com base nessa compreensão nos aproximamos dos estudos de Varela, Thompson e Rosch (2003) e passamos a considerar algumas experiências do movimento vividas nos ateliês como possibilidade de permitir uma reflexão incorporada da experiência do dançar. Ao discutirem sobre o método da atenção budista, os autores esclarecem que "Atenção significa que a mente está presente na experiência incorporada de cada dia; técnicas de atenção são projetadas para levar a mente de volta de suas teorias e preocupações, da atitude abstrata, para a situação da própria experiência da pessoa." (Varela, Thompson e Rosch, 2003, p.39). Essa ideia favorece a nossa pesquisa, na medida em que permite uma abordagem da experiência na dança, tendo como foco o estado meditativo. Essa atitude amplia nossa abordagem teórico-metodológica e considera o estado meditativo como possibilidade de levar o artista da dança a tornar-se atento, experimentar e contemplar a própria dança enquanto dança, sem apegar-se a modelos e estéticas de produção coreográfica. A pesquisa se amplia ao discutir esse estado corporal como possibilidade de uma presença que permite o artista escolher e acionar gatilhos diversos para a produção de sua própria dança e ao mesmo tempo encontrar-se ciente dessas descobertas e escolhas. A dança, como uma experiência meditativa do dançarino ou estado meditativo, apresenta uma possibilidade de compreensão da experiência do dançar em seus aspectos imediatos, que podem ser posteriormente palco de inúmeras reflexões através da produção das narrativas.

Das experiências de ensino investigadas na pesquisa, obtivemos vários relatos de alunos a partir dos quais podemos perceber a descrição de experiências de dança que fazem relação com as reflexões até então aqui apresentadas. Nesse contexto, consideramos como importante não somente a experiência do dançar e poder compreender a própria dança enquanto é dançada, mas também a vivência dessa experiência como referência para a criação de narrativas do dançar, uma vez que, a partir da narrativa, essas experiências podem ser discutidas e socializadas em grupo no espaço da sala de aula. A vivência com práticas que favorecem a experiência do presente ou o prolongamento dessa experiência tem sido tema de depoimentos dos alunos como possibilidade de ampliação das capacidades expressivas para a dança, como também da própria forma de compreensão da dança. Não como aprendizado de uma linguagem codificada, mas como uma abertura para a criação de uma poética, a exemplo da forma como Louppe (2012) faz uso desse termo. Nas palavras da autora: "A poética procura circunscrever o que, numa obra de arte, nos pode tocar, estimular a nossa sensibilidade e ressoar no imaginário, ou seja, o conjunto das 
condutas criadoras que dão vida e sentido a obra" (p.27). E acrescenta, "... revela-nos o caminho seguido pelo artista para chegar ao limiar onde o acto artístico se oferece à percepção, o ponto onde a nossa consciência a descobre e começa a vibrar com ela" (p.27). A poética abre-se ao mundo, tem desejo de partilha, "inclui percepção de seu próprio processo" (p. 27).

A discussão da poética no contexto da dança traz a reflexão sobre o corpo, pois sua existência não se faz pela mutação de códigos ou de uma nova forma de dizer em outras configurações estéticas, mas já de início retoma o ato de dançar circunscrito na consciência do indivíduo no mundo. Corroboramos as palavras de Louppe $(2012$, p. 69) que

\begin{abstract}
Ser bailarino é escolher o corpo e o movimento como campo de relação com o mundo, como instrumento de saber, de pensamento e de expressão. É também confiar o caráter lírico do orgânico, sem por isso lhe atribuir uma estética ou uma formação precisa: o movimento ou o estado do corpo neutro (voluntariamente acentuado e sem design) tem a sua própria qualidade lírica, tal como o movimento em tensão no espaço e tornado musical. O principal aspecto a ter em conta é trabalhar, em primeiro lugar, as condições orgânicas dessa emergência poética. Uma vez tomada esta opção fecunda, o corpo tornar-se-á uma admirável ferramenta de conhecimento e de sensações.
\end{abstract}

Entendemos que a criação dessa emergência poética se dá principalmente pelo reconhecimento das próprias experiências de movimento, de um olhar atento para elas, seja a partir da própria dança como possibilidade de vivência e prolongamento do presente, seja a partir de sua revisitação nas experiências de narrar como experiência, onde passado e futuro situados no presente escrevem novas perspectivas de conhecimento de si.

Nesse sentido, esperamos que esta investigação seja capaz de apontar perspectivas para a formação do professor da dança que partam primeiramente de sua própria experiência como ser dançante e de sua capacidade de socializar tal experiência na forma de narrativas, ações necessárias ao seu enlace criativo com o conhecimento produzido sobre o dançar e seu ensino. Entendemos também que essas ações podem contribuir com o fortalecimento de vínculos entre o professor de dança e a área de conhecimento, foco de sua ação pedagógica.

\title{
4. REFERÊNCIAS BIBLIOGRÁFICAS
}

1. ALARCÓN, M. Maxine Shhets-Johnstone: Fenomenologia da Dança. O Percevejo (On Line), v. 3, n.2, p. 4-13, 2011.

2. DA LIU. T'ai Chi Ch'uan e Meditação. São Paulo: Editora Pensamento, 2004.

3. DUTRA, E. A narrativa como uma técnica de pesquisa fenomenológica. Estudos de Psicologia, v. 7, n. 2, p. 371-378, 2002.

4. BENJAMIM, W. Magia e técnica, arte e política: ensaios sobre literatura e história da cultura. 8a Ed. São Paulo: Brasiliense, 2012. (Obras escolhidas, vol. 1)

5. CHAUÍ, M. Experiência do pensamento: ensaios sobre a obra de Merleau-Ponty. São Paulo: Martins Fontes, 2002.

6. HUANG, A. C. Expansão e recolhimento: a essência do T'ai Chi. São Paulo: Summus Editorial, 1979. 
7. LAUNAY, I. O dom do gesto. In: Greiner, C. Amorim, C. (Orgs.). Leituras do corpo. São Paulo: Annablume, 2010. (pp. 81-103)

8. LOUPPE, L. Poética da Dança Contemporânea. Lisboa: Orfeu Negro, 2012.

9. MACHADO, M. M. O diário de bordo como ferramenta fenomenológica para o pesquisador em artes cênicas. Revista Sala Preta, v. 1, n.2, p. 260-263, 2002.

10. MERLEAU-PONTY, M. A Fenomenologia da percepção. Rio de Janeiro: Martins Fontes, 1994.

11. MERLEAU-PONTY, M. A prosa do mundo. São Paulo: Cosac \& Naify, 2002.

12. MERLEAU-PONTY, M. Conversas- 1948. São Paulo: Martins Fontes, 2004.

13. PESSOA, F. (n.d.) Livro do Desassossego. Disponível em: http://www.dominiopublico.gov.br/download/texto/vo000008.pdf. Acesso em: 20/09/2014.

14. PORPINO, K. Dança é educação: interfaces entre Corporeidade e Estética. Natal: Editora da UFRN, 2006.

15. ROCHA, T. Por uma docência artista com Dança Contemporânea. In: GONÇALVES, T., BRIONTES, H., PARRA, D. \& VIEIRA, C. Docência - Artista do Artista - Docente. Fortaleza: Expresso Gráfica e Editora, 2012. pp. 32-49.

16. STERN, D. O momento presente na psicoterapia e na vida cotidiana. Rio de Janeiro: Record, 2007.

17. STRAZZACAPPA, M.; MORANDI, C. Entre a arte e a docência: a formação do artista da dança. Campinas, Papirus Editora, 2006.

18. STRAZZACAPPA, M. A formação do professor de dança. In: GONÇALVES, T., BRIONTES, H., PARRA, D. \& VIEIRA, C. Docência - Artista do Artista - Docente. Fortaleza: Expresso Gráfica e Editora, 2012. p. 20-31.

19. TERRA, A. Onde se produz o artista da dança? In: TOMAZZONI, A., WOSNIAK, C. \& MARINHO, N. Algumas perguntas sobre dança e educação. Joinville: Nova Letra, 2009. p. 67-76

20. VARELA, F., THOMPSON, E., ROSCH, E. A mente incorporada: ciências cognitivas e experiência humana. Porto Alegre: Artmed, 2003.

21. WOSNIAK, C. Bacharelado e/ou licenciatura: quais são as opções do artista da dança no Brasil? In: TOMAZZONI, A., WOSNIAK, C. \& Marinho, N. Algumas perguntas sobre dança e educação. Joinville: Nova Letra, 2009. p. 67-76 